\title{
LIFE-PATTERN STUDIES ON AN AUSTRALIAN \\ SPHINCTOMYRMEX (FORMICIDAE: PONERINAE; CERAPACHYINI): FUNCTIONAL POLYGYNY, BROOD PERIODICITY AND RAIDING BEHAVIOR.
}

\author{
By A. Buschinger, ${ }^{1}$ C. Peeters ${ }^{2}$ and R. H. Crozier ${ }^{2}$
}

\section{INTRODUCTION}

The ponerine tribe Cerapachyini comprises a considerable number of species (Brown, 1975), the life histories of which, however, are as yet poorly known (Hölldobler, 1982). All species so far investigated feed exclusively on other ants (Wilson, 1958, Brown, 1975), and several Cerapachys and Sphinctomyrmex species have been seen to conduct raids against colonies of a variety of ant genera and species. Hölldobler (1982) analyzed the organization of such raids in Cerapachys cf. turneri from North Queensland, and Wilson (1958) described a raid of Spinctomyrmex steinheili from Victoria. In the same paper, a few laboratory observations on $S$. caledonicus from New Caledonia were reported. According to Briese (1984) Sphinctomyrmex sp. in southwestern New South Wales raided nests of Chelaner sp., which evacuated their brood to temporary nest sites, but later reoccupied the original nests.

A remarkable feature of the Cerapachyini is the morphological diversity of their female reproductives, which range from ordinary winged to "ergatoid". In Sphinctomyrmex, according to Brown (1975), ergatoidy "has begun to converge towards the dichthadiiform condition of army ant queens". In the same genus, as in other cerapachyines the occurrence of multiple "ergatoid" females has been recorded, but it has been unclear whether or not all of them are functional queens (Brown, 1975).

Finally, a marked tendency towards brood periodicity and developmentally synchronized broods have been found in some Cerapachys and Sphinctomyrmex species (Wilson, 1958; Hölldobler, 1982).

1) Fachbereich Biologie, Institut für Zoologie, der Technischen Hochschule Darmstadt, Schnittspahnstr. 3, D-6100 Darmstadt, FRG

2) School of Biological Science, University of New South Wales, PO Box 1, Kensington NSW 2033, Australia

Manuscript received by the editor June 23, 1989. 
Although colony foundation has never been observed, and the question remains whether or not nomadic life habits occur, Brown (1975) states that "we probably see the early stages of developing army ant lifeways" in the Cerapachyini.

Here we report on our observations of a number of Sphinctomyrmex colonies in laboratory culture, which confirmed the first observations of brood periodicity. Some experiments revealed a certain degree of prey specificity, prey storage was observed (as in Cerapachys-Hölldobler, 1982), and dissections of ergatoid females clearly demonstrated functional polygyny in the species investigated. One colony with workers and queens was kept alive for more than a year.

\section{Materials AND Methods}

Three colonies (no. 1, 2, 3) were collected in New South Wales in November, 1987. They were aspirated as completely as possible. Voucher specimens of colonies 1 and 2 were deposited in ANIC, Canberra. Further material is stored in the collecting of A.B., with reference numbers 13628 (col. 1), 13653 (col. 2) and 13684 (col. 3).

Col. 1: 18 Nov. 1987, Hartley Vale, Blue Mountains (ca. 900 m), beneath a rock in relatively humid sclerophyll forest. The colony comprised about 400 adults, including about 20 ergatoid females, and no brood.

Col. 2: 24 Nov. 1987, Megalong Valley, near Mermaids Cave, Blue Mountains (ca. $1000 \mathrm{~m}$ ) beneath a rock in humid rainforest: 190 workers and 11 ergatoid females, about 100 eggs.

Col. 3: 26 Nov. 1987, Hassans Walls, near Lithgow, Blue Mountains (ca. $950 \mathrm{~m}$ ), beneath a rock in comparatively dry sclerophyll forest: ca. 80 workers, 9 ergatoid females, and a batch of eggs.

Colony 2 was preserved, and part of its queens and workers were dissected. The colonies 1 and 3 were housed first in Petri dishes of about $12 \mathrm{~cm}$ diameter, then transferred to Germany on December 14/15, 1987, in PVC-tube-nests (Buschinger and Heinze, 1988). Col. 1 was there placed into a maze as detailed in Fig 1, and col. 3 in a 3-chambered formicary (Buschinger, 1974). Water was provided in glass tubes, trapped behind cotton plugs, in one chamber of both the formicary and the maze. Foreign ant brood, pupae and larvae 
mainly of Amblyopone, later Myrmica and Monomorium, was regularly put into the formicaries so that some food was always present. Temperatures were fluctuating daily between 20 and $30^{\circ} \mathrm{C}$ with occasional peaks of $35^{\circ}$ in the afternoon. Dissections of females and workers followed Alloway et al. (1982).

\section{RESULTS}

\section{a) Identification}

Samples of colony 1 and 2 were identified as Sphinctomyrmex cf. steinheili by R. W. Taylor. Col. 3 specimens look identical to those from col. 1, being entirely dark brown, whereas all the workers and queens of col. 2 are light brown in coloration. Col. 2 specimens also appear somewhat more sculptured than those of col. 1 and 3, having a very fine pattern, between the foveolae of dorsum of head and thorax, as compared to col. 1 and 3 specimens in which these spaces are smooth and shining. Colony 2 thus might represent a different taxon. The biological data, however, are consistent for all three colonies.

b) Functional polygyny

A total of 20 ergatoid females (Col. 1: 6; Col. 2: 5; Col. 3: 9) and 17 workers were dissected mostly soon after collecting, during an egg-laying period. All ergatoids had the receptacles full of sperm, except one specimen from col. 1 which had enlarged ovaries with developing oocytes, and conspicuous corpora lutea, but either was unmated or had run out of sperm, and in three specimens from col. 3 the spermathecae were empty. In the latter, the ovarioles were only faintly visible, very short and translucent, and no corpora lutea could be detected. Presumably they had never mated.

The remaining sixteen females were all fully fertile, having ovarioles which, when straightened out, were as long as both gaster and petiolus of the females. Growing and mature oocytes, and corpora lutea indicating previous egg-laying, were present in most of the ovarioles. This was observed in all except four females of col. 3 dissected in June 1988 (seven months after the last eggs had been laid in this colony), where no growing oocytes were found, although corpora lutea were still visible. This together with the big egg masses found at the beginning of laboratory observation clearly indicates that several functional queens were present in each of the 3 colonies, the species thus being polygynous. 
The numbers of ovarioles in females varied between 2 and 5 in each ovary. One queen each had $2+2$ and $3+3$ ovarioles, seven had $4+4$, four each had $5+4$ and $5+5$, one had $6+5$, and in two females the number could not be established. In workers usually $1+1$ ovarioles were found (in two specimens they were not detected, or were absent), and no spermatheca was present. The worker ovarioles in most instances were short, fine and translucent, only one worker of col. 1 and of col. 2 each had a growing oocyte in one of their ovarioles.

Between 5 and 7 Malpighian tubules were recorded in both workers and queens. In queens, the oesophagus within the thorax was slightly extended, but did not form a wide thoracic crop as found in many other ant queens (Petersen-Braun and Buschinger, 1975).

c) Brood periodicity and development

As stated above, col. 1 was collected on 18 Nov. without eggs, whereas in col. 2 and 3, found six and eight days later, eggs were already present in the field. In col. 1, eggs appeared from 19 Nov. onwards with numbers increasing up to several hundred until 22 November. Thus, in all three colonies the first batch of eggs after the winter was laid fairly simultaneously.

Larvae started to hatch in col. 1 on 30 Nov. thus only nine days after the first eggs had been observed. From a second batch of eggs laid in January, 1988 (see below) the first larvae hatched after 12 days, perhaps because of somewhat lower temperatures.

On 20 December, 1987, no more eggs, but an estimated 130 larvae were present in col. 1, and on 21 December some 10 pupae were recorded. Thus larvae also develop quickly (in about 3 weeks). In col. 3 the first pupae were found 36 days after egg-laying, and 24 days after the first larvae had hatched.

Pupal development in col. 1 also took 3 weeks, the first newly eclosed specimens being recorded on 18 January, 1988. In total, the development time from egg to the adult is thus about 60 days. The number of cocoons, however, was considerably lower than that of larvae (41 pupae from ca. 130 larvae), and the premature opening of cocoons and consumption of pupae was repeatedly observed. This was presumably caused by inappropriate rearing conditions. Most (perhaps all) of the young adults were ergatoid females, and no males emerged from the broods. 
A second batch of eggs was laid in col. 1 beginning on 13 January, 1988 , thus shortly before the pupae began to hatch. Eggs then were recorded for 17 days, and a number of larvae from 25 January on, thus 12 days after the beginning of egg-laying. Until the end of January, however, the numbers of eggs and larvae decreased rapidly, and none of the larvae pupated.

After the second brood in col. 1, and the first brood in col. 3, further egg-laying did not occur, and on 23 November 1988 the last queen died and the last workers of col. 1 were preserved.

d) Raiding behavior, prey specificity and storage

Colony 1 was housed in a maze (Fig. 1) especially constructed for the observation of Sphinctomyrmex when confronted with various other ant species. The main purpose of the experiments was to find an appropriate prey species, so that the colony would resume reproduction, since egg-laying and brood development ceased when the supply of Amblyopone australis pupae ran out in January. Among various ant species tested the pupae of $A$. australis appeared the most attractive food for the Sphinctomyrmex during the first two months of observation, and in the field, A. australis was found in

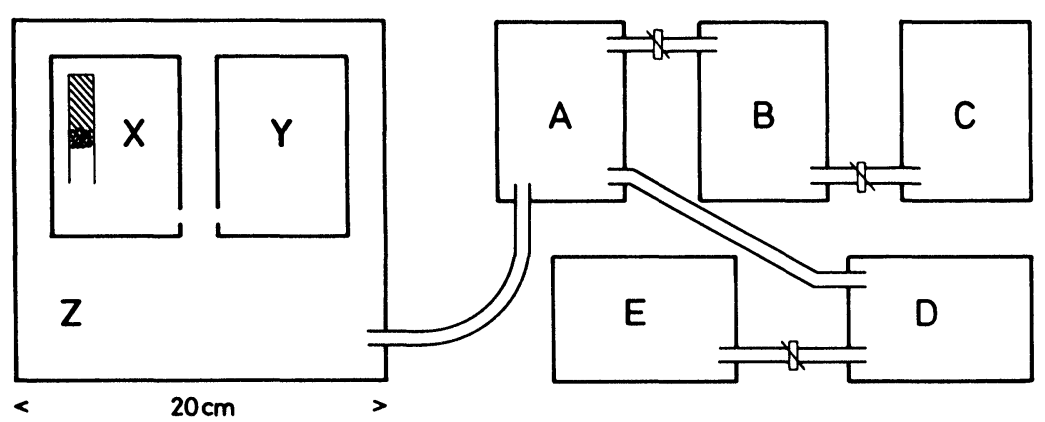

Fig. 1. A maze constructed for observations of Sphinctomyrmex colony 1. All chambers are cast out with a layer of plaster of Paris $(.5-1 \mathrm{~cm})$ which was covered with fine sand. The walls were coated with liquid paraffin. All compartments were covered with lids having a hole $(2 \mathrm{~cm}$ diameter) onto which a wire gauze was welded, for ventilation. The "main chamber" also was covered with such a lid, and illumination of all the system was reduced with a sheet of paper covering it. Water was supplied in compartment $X$, and the plaster ground in all compartments was kept humid. Some clamps are indicated in the PVC-tubes connecting the compartments. 
the soil or beneath rocks in very close proximity $(30 \mathrm{~cm}-1 \mathrm{~m})$ to the three Sphinctomyrmex colonies.

Raiding and foraging behavior itself were thus observed only incidentally, but a number of interesting details may be reported.

During the first rearing of larvae in December, 1987, all kinds of ant brood were consumed in the Sphinctomyrmex colonies, such as larvae and pupae of Myrmecia spp., Monomorium cf. rubriceps, other Monomorium species, Meranoplus spp., and the obviously most preferred Amblyopone australis. In addition, pieces of mealworm were chewed, which is the first record of a diet different from ants. On one occasion, about 30 Sphinctomyrmex fed on a piece of Tenebrio pupa, despite the presence of Myrmica brood in their nest (see below).

After the transfer of the colonies to Germany, experiments were run with several European ant species, mainly Myrmica ruginodis, Leptothorax muscorum, and Lasius niger. In addition, material was available from laboratory colonies of Australian Monomorium cf. rubriceps. Generally, ant pupae were preferred over larvae which were only attacked once no more pupae were present. Often larvae or prepupae were carried into the Sphinctomyrmex nest, where they were stored until pupation, and the pupae then devoured. Dead adult ants also were consumed, and Sphinctomyrmex larvae were placed for feeding onto such prey items.

When adult ants were placed singly into the main chamber of the maze, or into the Petri dishes containing a Sphinctomyrmex colony, all species of foreign ants including Amblyopone, Monomorium, Myrmica, or a Lasius niger queen, were immediately attacked and killed within a few seconds, despite being (much) larger than the Sphinctomyrmex (Fig. 2). After having detected an "intruding" ant, one or two $S$. workers circled around the victim very rapidly, with erratic movements, perhaps releasing an alarm pheromone or marking the surrounding area. Very soon a number of nestmates approached, and tried to grasp the legs of the foreign ant, and to sting her. With large prey ants, stinging evidently was possible into the appendages only, because it is only there that the Sphinctomyrmex were able to keep a firm hold with their tiny mandibles.

In the maze (Fig. 1), the majority of col. 1, including its brood, was usually in the compartment $X$, or in front of it (site marked " $Z$ " in Fig. 1). In the compartment $A$ to $E$ colony fragments of prey 


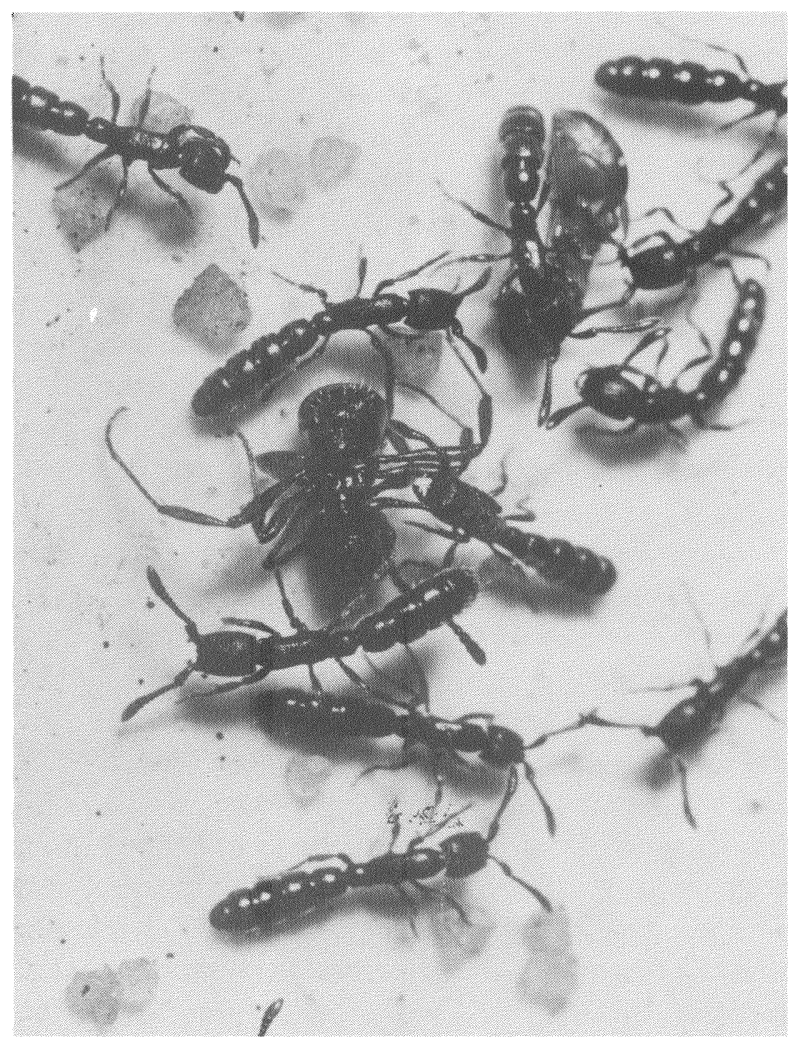

Fig. 2. Attack of Sphinctomyrmex on a Myrmica ruginodis worker.

species were offered. The diameter of connecting tubes could be reduced, with tube-clamps, so that the Sphinctomyrmex were able to pass, but the larger prey ants were confined to their respective compartment.

After a few preliminary experiments had revealed that foreign ants confined in compartments A or B were soon detected and attacked by Sphinctomyrmex, the prey items later were always placed into $\mathrm{C}$ or $\mathrm{E}$.

While recruitment towards prey "colonies" could never be directly observed, our data strongly suggest that an effective recruitment system exists. After a group of prey ants (5-20 workers and brood) was placed in one of the compartments, and the connecting tube 
opened sufficiently to allow the Sphinctomyrmex to pass, usually one or two Sphinctomyrmex workers were seen during the first hours of observation, wandering to and fro between the nest and the prey compartment, or sometimes "scouting" inside the latter. Recruitment presumably took place during the night, since often a high number (up to 50) of Sphinctomyrmex were crowding the respective compartment the following morning. With Myrmica ruginodis as prey, all adults had been killed, and the corpses as well as the Myrmica pupae and larvae were mostly carried as far as the narrow passage in the tube. When the tube-clamp was opened, the Sphinctomyrmex quickly carried the booty to their nest.

In one experiment, a Myrmica colony fragment was offered in compartment E, and a group of 20 Monomorium cf. rubriceps workers with Myrmica pupae was placed simultaneously in C. After two days, the Myrmica workers in E were dead, and their brood had been removed, whereas Monomorium had not been attacked. They remained unharmed for a further 4 days, whereas two other $M y r-$ mica groups in $\mathrm{E}$ and $\mathrm{D}$ were raided during this time.

Prey ants and their broods (larvae and pupae) were usually carried into the Sphinctomyrmex nest. Ant corpses were quickly cut in pieces and then soon discarded outside the nest. Pupae were chewed and eaten apparently according to the actual needs in the colony (they sometimes remained intact for up to a week) whereas foreign larvae usually were not consumed before all pupae were eaten.

Once, a surplus of Myrmica and Monomorium pupae had been supplied (Fig. 3), at a time when Sphinctomyrmex larvae were no longer present. Two workers of $M$. cf. rubriceps then eclosed within the Sphinctomyrmex nest, but were soon attacked and killed. This observation is remarkable, since Cerapachys stings prey brood, and apparently prevents its further development (Hölldobler, 1982). We did not see whether or not Sphinctomyrmex actually stings captured brood, although stinging movements towards them were usually observed. However, if stinging occurs, it apparently does not stop the development of the prey pupae.

Fig. 3 (opposite page). Part of Sphinctomyrmex colony 1, with prey brood (larvae, prepupae, pupae of Monomorium cf. rubriceps). The sand hill (upper left corner) in front of the entrance to one of the compartments had been piled up by the ants. 


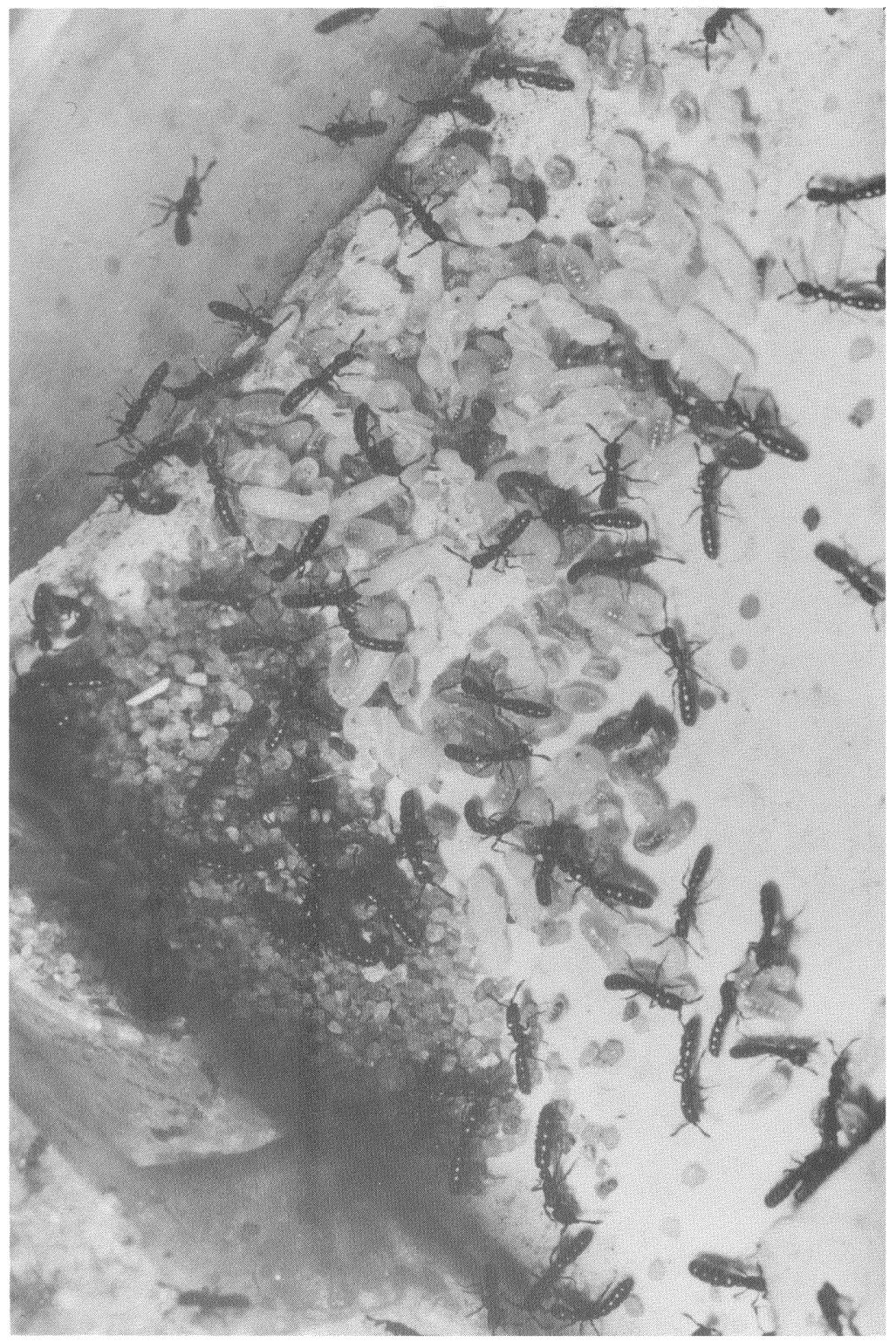


e) Nest relocation

The maze with colony 1 was also designed for finding out whether Sphinctomyrmex would move into the "nest" of a prey species, in case that transportation of the booty from it to their nest was not possible. In all the experiments, however, where the prey ants were placed in the compartments $\mathrm{C}, \mathrm{D}$ or $\mathrm{E}$, and where the narrow passages prohibited their being carried away, the Sphinctomyrmex never exhibited any tendencies to move into the respective compartment.

Nevertheless, several nest relocations occurred spontaneously: From January 13 onwards the colony remained in X for 3 weeks; the ants moved to $\mathrm{Y}$ on 2nd February, taking Myrmica brood with them, then, the same day, moved to $\mathrm{Z}$, where they remained for 10 days. On February 12 the colony moved to $X$, three days later back to $Z$, the next day to $X$, where it remained for 26 days until March 14. On this day, the colony split up, most of it moving to $D$ (where, however, no prey ants had been offered for the preceding 3 weeks), but a few remaining in $\mathrm{X}$ with some large Myrmica-pupae, and

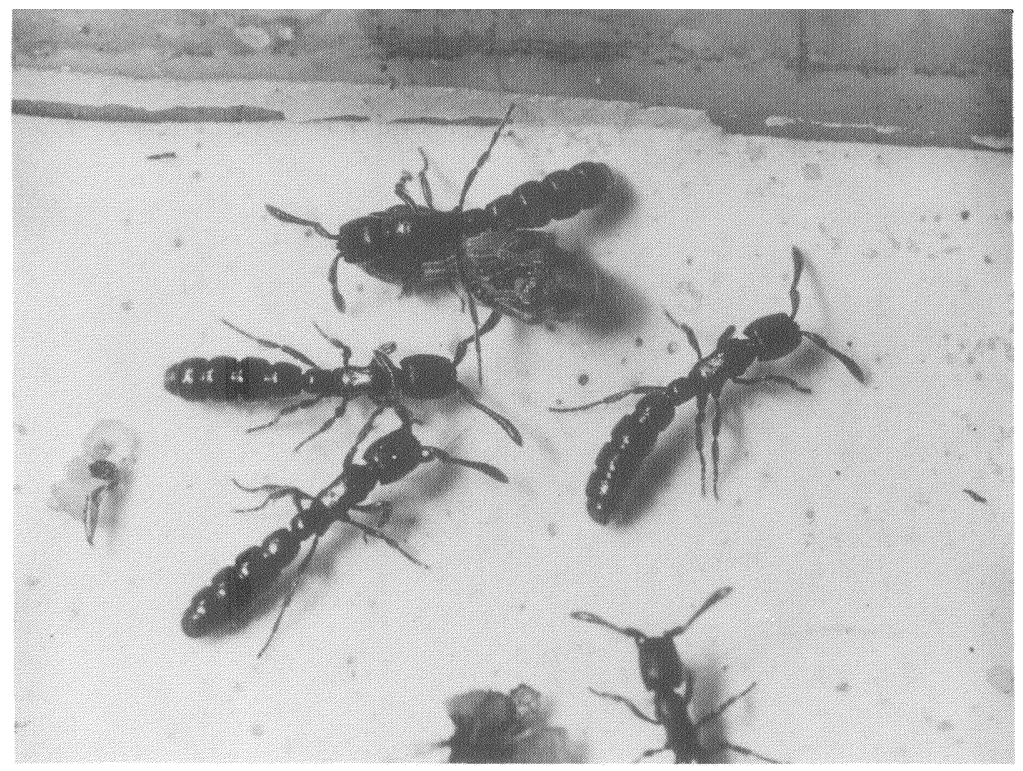

Fig. 4. A Sphinctomyrmex worker carrying a prey pupa under the body. 
another small group moving to A. Ten days later all the colony with the prey brood assembled there.

Several of these nest relocations were directly witnessed. As was earlier described for Cerapachys, (Hölldobler, 1982), Sphinctomyrmex workers carry their own larvae or pupae as well as prey brood longitudinally under their bodies, between the legs, like true army ants (Fig. 4).

A final observation refers to a rudimentary construction behavior. In all the compartments of the maze a layer of fine sand had been strewn over the plaster of Paris bottom. Some of this sand was carried and piled up by Sphinctomyrmex workers, e.g. in front of the entrance to chamber X (Fig. 3), or at the entrance of the tube connecting the large compartment with A. Also a lot of sand was carried into the tubes often filling them up so much that the passage with booty became difficult.

\section{Discussion AND CoNCLUSIONS}

An important result of this study is the demonstration of true polygyny occurring in multiple-female colonies of Sphinctomyrmex. Since we also have dissected the four resp. two dealate females of two Cerapachys sp. colonies and found them to be inseminated and fertile, we may conclude that the often-reported multiple-female colonies in Cerapachyini in fact are usually polygynous.

The study further revealed that in Sphinctomyrmex workers have simple ovaries consisting of only two ovarioles, and they lack a spermatheca as in many ants of higher subfamilies. This is remarkable because in a variety of ponerine genera workers usually have 3-4 ovarioles/ovary, and often all individuals have a spermatheca (Peeters, 1987).

As in the Cerapachys species investigated by Hölldobler (1982), prey storage was also observed in Sphinctomyrmex, though only for shorter periods. In contrast to Cerapachys, the Sphinctomyrmex colony did not stop raiding when sufficient prey was in the nest. All prey colonies were attacked soon after access was gained to the respective compartment. Recruitment for raids, or during nest relocation, was not directly observed, but evidence suggests that a recruitment communication similar to that in Cerapachys exists also in Sphinctomyrmex. 
With respect to prey species, the Sphinctomyrmex studied appears not to be highly specific, since a variety of ant species were attacked, among them Myrmica which do not naturally occur in Australia. Monomorium cf. rubriceps was not attacked, presumably because of an effective defensive secretion, but its brood was eaten, as was that of any other ant species provided. Surprisingly, pieces of Tenebrio larvae and pupae were also eaten, and we therefore cannot exclude the possibility that Sphinctomyrmex might occasionally exploit other dead insects, too.

One colony survived for a year under the conditions as described, but reproduction stopped after 2 months, during a second brood period in the laboratory. The larvae did not complete their development, and having laid the second batch of eggs the queens did not resume egg-laying later. This failure may have various reasons, but diet may be involved, since reproduction ended when no more Amplyopone pupae could be supplied, all other conditions remaining alike. Further studies will be necessary to check whether a particular prey is necessary for maintaining the fertility of Sphinctomyrmex queens.

Some of our observations correspond with the suggestions of Wilson (1958) and Brown (1975), namely that early stages of army ant behavior may be represented in cerapachyine ants. As did these authors, and Hölldobler (1982), we also found a marked brood periodicity, the army-ant-like carrying behavior of brood under the body, and frequent nest relocation, the latter without periodicity, however.

More important, the morphology and biology of the queens apparently also tend towards army-ant features. As mentioned above, Brown (1975) found a morphological cline in Sphinctomyrmex ranging from winged "females with large eyes, ocelli, etc. to blind subdichthadiiform queens", with $S$. cf. steinheili representing an intermediate condition: They "have compound eyes of moderate size and 3 ocelli, but workerlike trunk" (Brown, 1975).

We emphasize here that because of the ergatoid condition of the queens which lack wing muscles that can be resorbed to feed the first generation of workers, and the myrmecophagous life habits, independent colony foundation by single females is quite improbable. Instead, we assume that new colonies of Sphinctomyrmex cf. steinheili and other polygynous species of this genus are formed through 
budding. Thus this process would be a highly probable and logical precursor of the colony multiplication as found in true army ants. The only additional requirement for the transition from polygyny with ergatoid females, which certainly mate within or close to the nest, to the monogynous army ant system would be that budding occurs soon after, or just before, the young females mate. The existence of probably monogynous Sphinctomyrmex species with "subdichthadiiform queens" (Brown, 1975) suggests that this transition may have already occurred within this genus. Therefore, it will be highly interesting in future investigations of cerapachyine species to assess their strategy of colony reproduction.

\section{SUMMARY}

Three colonies ranged in size from approximately 80 to 400 adult workers and nine to 20 ergatoid females. Sixteen of 20 ergatoid females dissected contained sperm, while the workers lacked spermathecae. The presence of corpora lutea and developing oocytes showed that these sixteen ergatoids were fully functional reproductives. This species is therefore polygynous. Laboratory and field data indicate that eggs were laid more or less simultaneously in all three colonies.

Although the ants ate fragments of mealworm in addition to brood of the Australian ant species Monomorium cf. rubriceps and the European ants Myrmica ruginodis, Leptothorax muscorum and Lasius niger, successful reproduction seemed to require Amblyopone australis, a syntopic species, as prey.

Adult workers of all species except Monomorium rubriceps were raided readily, but the latter were avoided. The Sphinctomyrmex did not move nest to the site of prey items, even when they are prevented from bringing these from another experimental chamber to their own, although nest-moving occurred at other times. Raiding behavior did not appear to be inhibited by the presence of food in the nest, but rather to be elicited whenever a suitable prey colony was encountered. Indirect evidence indicates that recruitment efficiency is similar to that seen in Cerapachys species.

This Sphinctomyrmex species thus exhibits various rudiments of army-ant life history, as noted previously by Wilson (1958) and Brown (1975). 


\section{ACKNOWLEDGMENTS}

This work was kindly supported by a grant of the Deutsche Forschungsgemeinschaft to A. Buschinger and Australian Research Council to R. H. Crozier. We are grateful to R. W. Taylor, Canberra, for the identification of the ants.

\section{REFERENCES}

Alloway, T. M., Buschinger, A., Talbot, M., Stuart, R., and Thomas, C.

1982. Polygyny and polydomy in three North American species of the ant genus Leptothorax Mayr (Hymenoptera: Formicidae. Psyche 89: 249-274.

BRIESE, D. T.

1984. Interactions between a myrmecophagous ant and a prey species. J. Aust. ent. Soc. 23: 167-168.

Brown, W. L., JR.

1975. Contribution toward a reclassification of the Formicidae. V. Ponerinae, Tribes Platythyreini, Cerapachyini, Cylindromyrmecini, Acanthostichini, and Aenictogitini. Search 5: 1-115.

BusChinger, A., AND Heinze, J.

1988. Practical tube nests for transportation and mailing of live ant colonies. Ins. Soc. 35: 206-208.

HÖLLDOBLER, B.

1982. Communication, raiding behavior and prey storage in Cerapachys (Hymenoptera; Formicidae). Psyche 89: 3-23.

Peeters, $\mathrm{C}$.

1987. The diversity of reproductive systems in ponerine ants. In: Eder, J. and Rembold, H. (eds) Chemistry and Biology of Social Insects. Verlag J. Peperny, Munich, pp. 253-254.

Petersen-Braun, M., and Buschinger, A.

1975. Entstehung und Funktion eines thorakalen Kropfes bei FormicidenKöniginnen. Ins. Soc. 22: 51-66.

WILSON, E. O.

1958. Observations on the behavior of the cerapachyine ants. Ins. Soc. 5: 129-140. 

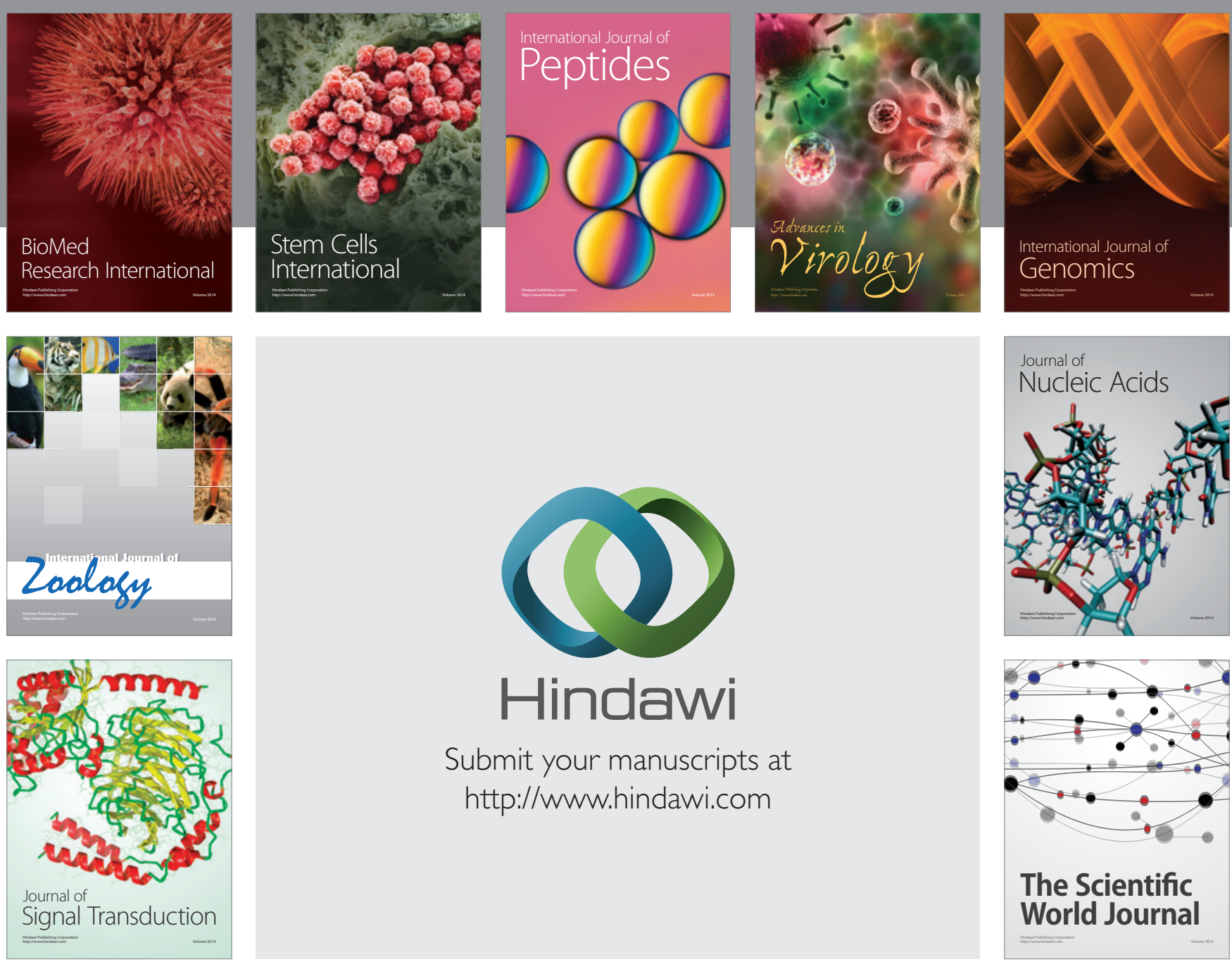

Submit your manuscripts at

http://www.hindawi.com
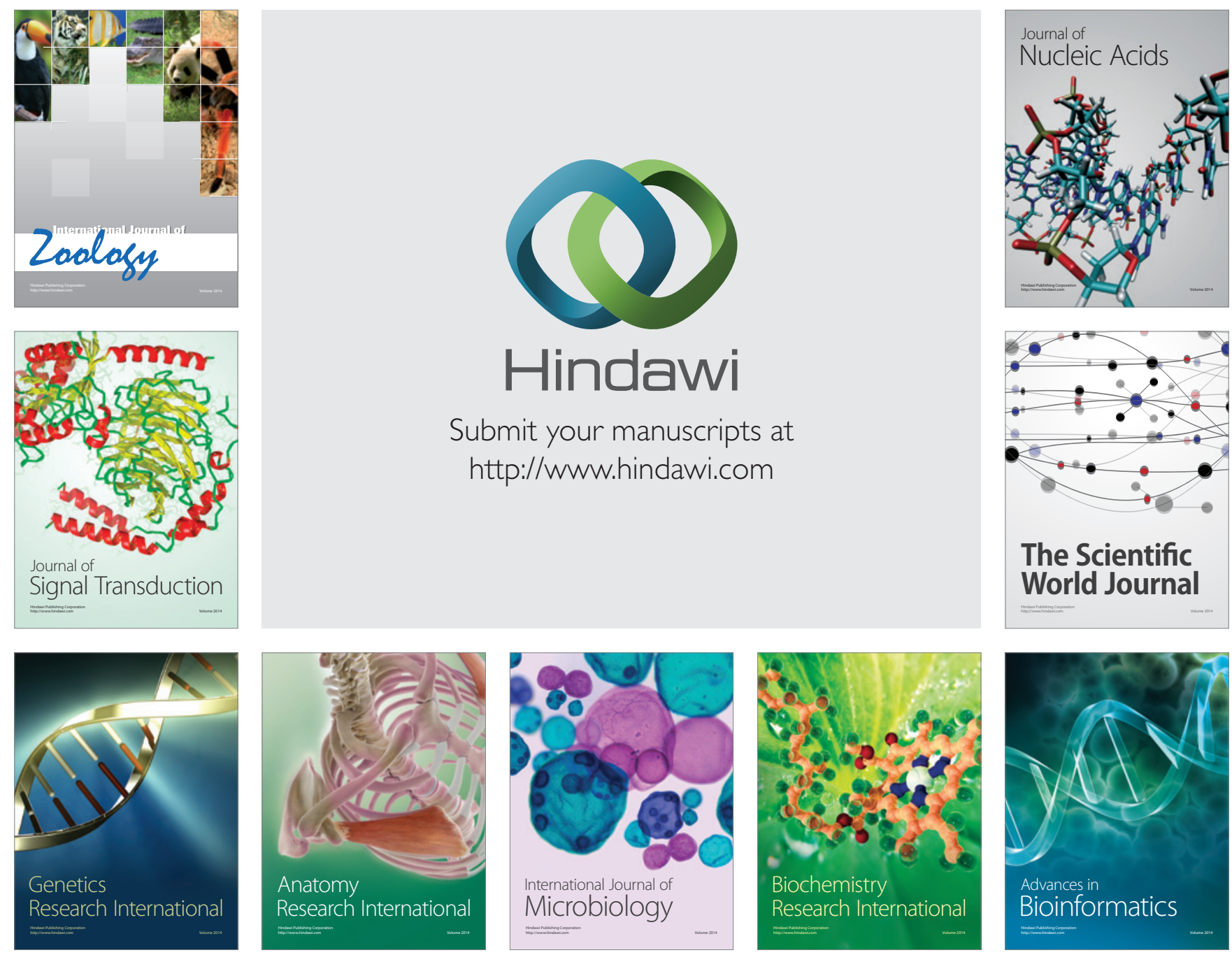

The Scientific World Journal
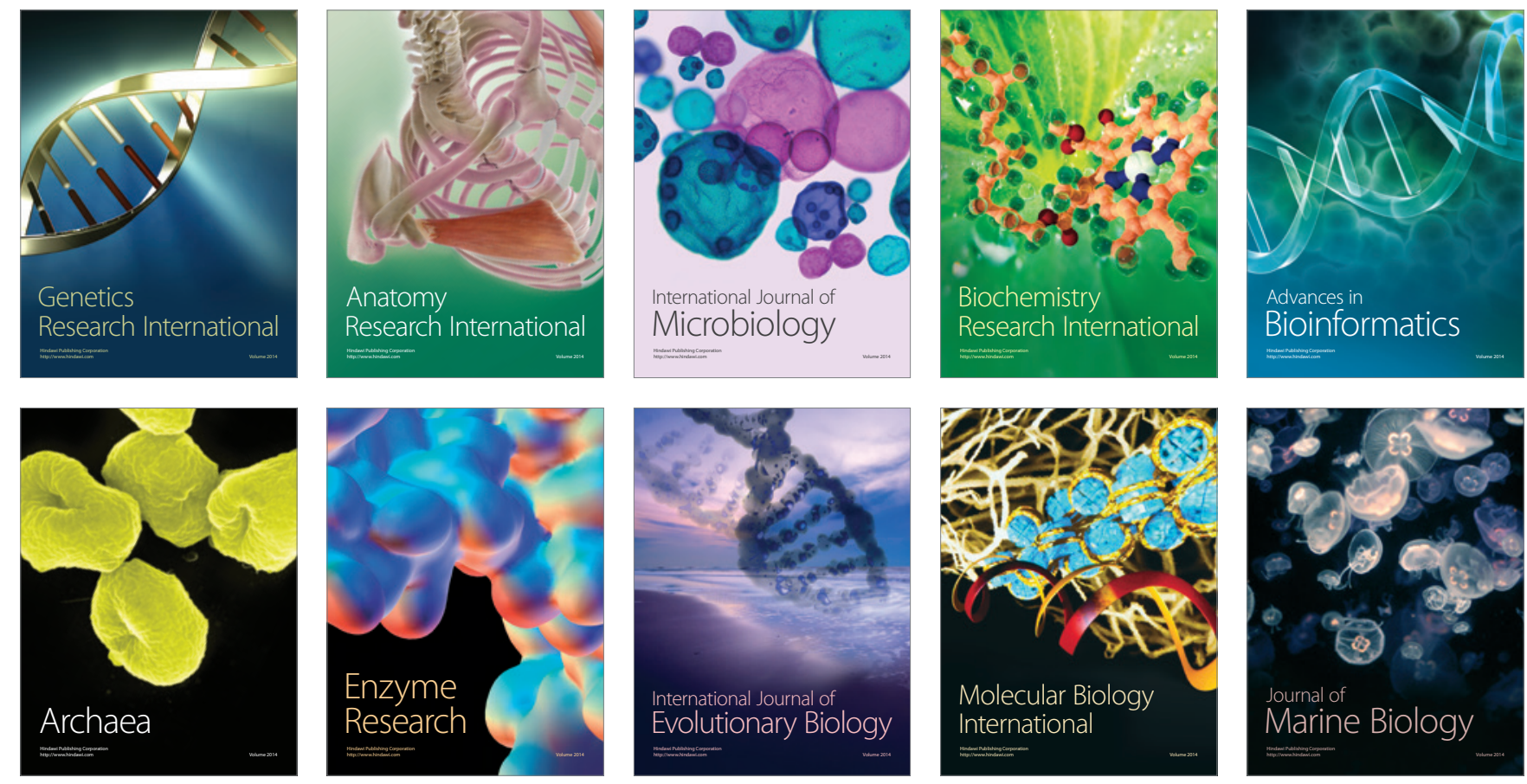